\title{
Kinetics of static strain aging in polycrystalline NiAl-based alloys
}

\author{
M. L. Weaver, ${ }^{a}$ M. J. Kaufman ${ }^{a}$ \& R. D. Noebe ${ }^{b}$ \\ "Department of Materials Science and Engineering, University of Florida, Gainesville, Fl 32611-2066, USA

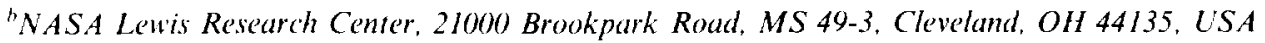

(Received 26 January 1995; accepted 13 February 1995)

\begin{abstract}
The kinetics of yield point return have been studied in two NiAl-based alloys as a function of aging time at temperatures between 300 and $700 \mathrm{~K}$. The results indicate that the upper yield stress increment, $\Delta \sigma_{u}$ (i.e., stress difference between the upper yield point and the final flow stress achieved during prestraining), in conventional purity (CP-NiAl) and in high purity carbon-doped (NiAl-C) material first increased with a $t^{23}$ relationship before reaching a plateau. This behavior suggests that a Cottrell locking mechanism is the cause for yield points in NiAl. In addition, positive 1 -axis intercepts were observed in plots of $\Delta \sigma_{u}$ versus $t^{2 \cdot 3}$ suggesting the operation of a Snoek mechanism. Analysis according to the Cottrell-Bilby model of atmosphere formation around dislocations yields an activation energy for yield point return in the range 70 to $76 \mathrm{~kJ} / \mathrm{mol}$ which is comparable to the activation energy for diffusion of interstitial impurities in bcc metals. It is, thus, concluded that the kinetics of static strain aging in NiAl are controlled by the locking of dislocations by Cottrell atmospheres of carbon atoms around dislocations.
\end{abstract}

Kevwords: A. nickel aluminides, based on NiAl, B. microalloying. B. strainaging. B. yield stress.

\section{INTRODUCTION}

It is generally accepted that bcc metals, in the presence of sufficient levels of interstitials, are subject to a strain aging phenomenon caused by elastic interactions between interstitial atoms and dislocations. The specific mechanisms by which this behavior occurs may involve Snoek ordering, ${ }^{1,2}$ Cottrell aging, ${ }^{3}$ Suzuki locking, ${ }^{4}$ or precipitation on dislocations. In spite of the large number of papers dealing with strain aging, few discuss aspects of strain aging in ordered bcc alloys even though several manifestations of dynamic and static strain aging have been identified as playing a role in the deformation of polycrystalline and single crystal B2 intermetallic compounds. In the intermetallic compounds $\mathrm{AgMg}, \mathrm{FeCo}, \mathrm{FeAl}$, and $\mathrm{NiAl}$, for example, the occurrences of sharp yield points and serrated stress-strain curves, ${ }^{5-16}$ strain rate sensitivity minima, ${ }^{17} 19$ yield stress plateaus as a function of temperature $^{20}$ and flow stress transients on changes in strain rate ${ }^{18.21}$ have been reported. In addition, extensive work by Margevicius et al. ${ }^{7.22} 24$ on $\mathrm{NiAl}$ has shown that a sharp yield point can be formed in binary $\mathrm{NiAl}$ following annealing at $1100 \mathrm{~K}$ and furnace cooling. This yield point can be removed by subsequent prestraining of the material by hydrostatic pressurization prior to testing and recovered by aging the prestrained material for $7200 \mathrm{~s}$ (i.e., 2 h) at 673 K. Similarly, Pascoe and Newey ${ }^{17}$ observed the formation of room temperature yield points in near stoichiometric $\mathrm{NiAl}$ annealed for $3600 \mathrm{~s}(1 \mathrm{~h})$ at $350 \mathrm{~K}$ following a uniaxial prestrain. In addition, recent investigations of static $^{12.25}$ and dynamic ${ }^{11}$ strain aging have shown that discontinuous yielding, in the form of yield points, yield plateaus and serrated yielding were observed in alloys containing high interstitial concentrations, particularly high carbon concentrations. ${ }^{12,25}$ These phenomena were not observed in low interstitial high purity or in nitrogen doped material ${ }^{11.12,25}$ suggesting that strain aging in NiAl 
carbon atoms. Despite these observations, no complete investigation of classical strain aging has been conducted on ordered bcc intermetallic alloys. Consequently, the purpose of this paper is to describe the results of a detailed study on the kinetics of static strain aging in polycrystalline $\mathrm{NiAl}$. Details of the influence of strain aging on the flow and fracture behavior of $\mathrm{NiAl}$ are provided in a previous document ${ }^{12}$ and in a companion paper. ${ }^{25}$

\section{EXPERIMENTAL}

\section{Materials}

The alloys used in this study were prepared by extrusion of: (1) a nominally stoichiometric conventional purity induction melted ingot (CP$\mathrm{NiAl}$, and (2) a carbon-doped and zone-leveled ingot (NiAl-C). Both starting materials were extruded at $1200 \mathrm{~K}$ with the $\mathrm{CP}-\mathrm{NiAl}$ and the NiAl-C ingots receiving $16: 1$ and $12: 1$ reduction ratios respectively. The as-extruded microstructures were fully dense consisting of recrystallized and equiaxed grains. The resulting compositions and as-extruded grain sizes are presented in Table 1.

Chemical analyses of the extruded materials were conducted at the NASA-Lewis Research Center by the following techniques deemed to be the most accurate for the particular elements. Ni and $\mathrm{Al}$ were determined using analytical wet chemistry/titration techniques and $\mathrm{Si}$ was determined by inductively coupled plasma atomic emission spectroscopy. Oxygen, nitrogen, carbon and sulfur contents were determined by combustion techniques using LECO oxygen/nitrogen and carbon/sulfur determinators. Additional details concerning materials processing and the chemical analysis techniques are presented elsewhere. ${ }^{12,25}$
Round button-head tensile specimens were ground from the extruded rods so that the gage lengths of the samples were parallel to the extrusion direction. Sample dimensions were $3.1 \mathrm{~mm}$ for the tensile gage diameters and $30.0 \mathrm{~mm}$ for the tensile gage lengths. Prior to testing, all samples were electropolished in a $10 \%$ perchloric acid-90\% methanol solution that was cooled to $208 \mathrm{~K}$.

\section{Mechanical testing}

Tensile tests were performed on an Instron Model 1125 load frame at a constant crosshead velocity corresponding to an initial strain rate of $1.4 \times$ $10^{-4} \mathrm{~s}$. True stress-strain data were calculated from the load-time plots. All tests were performed in air at $300 \mathrm{~K}$.

The kinetics of strain aging were investigated using the classic yield point return technique. Testing was conducted in two steps: (1) Initially, tensile specimens in the as-extruded condition were prestrained approximately $0.2 \%$ at room temperature, unloaded to a stress of approximately $2 \mathrm{MPa}$, aged in situ on the load frame at elevated temperatures for aging times varying between 60 and $113000 \mathrm{~s}(30 \mathrm{~h})$, and then tested in tension at room temperature. This test method allows specimen alignment to be maintained and the stress level to be kept effectively constant during aging. After aging, the specimens were cooled by removing the furnace from the test frame and passing a forced stream of ambient air over the specimen and the tensile grips. This method of cooling resulted in average temperature drops of 500 to $1000 \mathrm{~K}$ during the first minute of cooling. The parameters used to evaluate the kinetics of strain aging are illustrated in Fig. 1. These include the upper yield stress increment $\Delta \sigma_{\mathrm{u}}$ $=\sigma_{\mathrm{u}}-\sigma_{\mathrm{a}}$, the lower yield stress increment $\Delta \sigma_{\mathrm{L}}=$ $\sigma_{\mathrm{L}}-\sigma_{\mathrm{a}}$, and the Lüders strain $\epsilon_{\mathrm{L}}$. (2) Single speci-

Table 1. Compositions of extruded NiAl alloys (atomic percent)

\begin{tabular}{|c|c|c|c|c|c|c|c|c|}
\hline \multirow{2}{*}{$\begin{array}{l}\text { Alloy } \\
\text { (heat) }\end{array}$} & \multirow{2}{*}{$\begin{array}{l}\text { Grain size } \\
\quad(\mu \mathrm{m})\end{array}$} & \multicolumn{7}{|c|}{ Impurities } \\
\hline & & $\mathrm{Ni}^{a}$ & $\mathrm{Al}^{*}$ & $\mathrm{Si}^{h}$ & $\mathrm{C}^{c}$ & $\mathrm{O}^{d}$ & $\mathbf{N}^{d}$ & $\mathbf{S}^{c}$ \\
\hline $\begin{array}{l}\text { CP-NiAl } \\
\text { (L2971) }\end{array}$ & $19 \pm 2$ & $50.0 \pm 0.2$ & $49 \cdot 7 \pm 0.2$ & 0.15 & 0.0147 & 0.0070 & $<0.0009$ & $<0.0007$ \\
\hline $\begin{array}{l}\text { NiAl-C } \\
\text { (L2988) }\end{array}$ & $45 \pm 4$ & $50 \cdot 2 \pm 0.2$ & $49 \cdot 8 \pm 0 \cdot 2$ & 0.05 & 0.0092 & 0.0030 & $<0.0009$ & $<0.0007$ \\
\hline
\end{tabular}

"Analysis performed using analytical wet chemistry/titration techniques, relative accuracy $\pm 1 \%$.

${ }^{h}$ Analysis performed on an ultraviolet/visible spectrophotometer, Shimadzu, Model UV-160, relative accuracy $\pm 10 \%$.

'Analysis performed on a simultaneous carbon/sulfur determinator, LECO Corp., Model CS-244, relative accuracy \pm 10 " $\%$.

'Analysis performed on a simultaneous nitrogen/oxygen determinator, LECO Corp., Model TC-136 or Model TC-436, relative accuracy $\pm 10 \%$. 


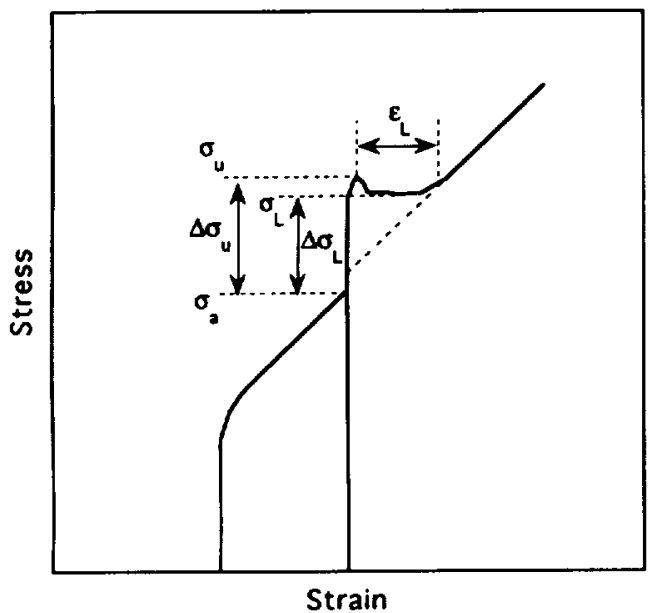

Fig. 1. Definition of strain-aging parameters.

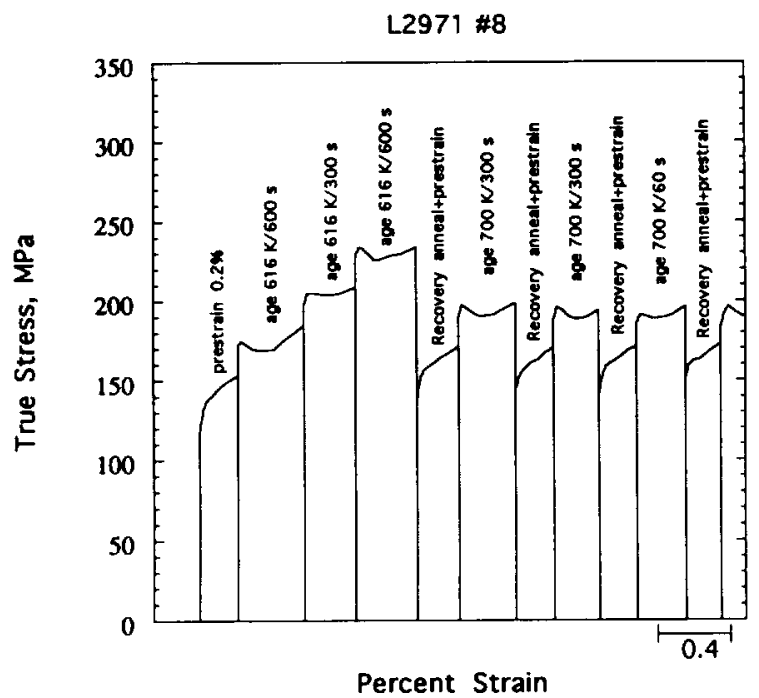

Fig. 2. Series of stress-strain curves illustrating the test method used to determine the strain aging kinetics in $\mathrm{NiAl}$.

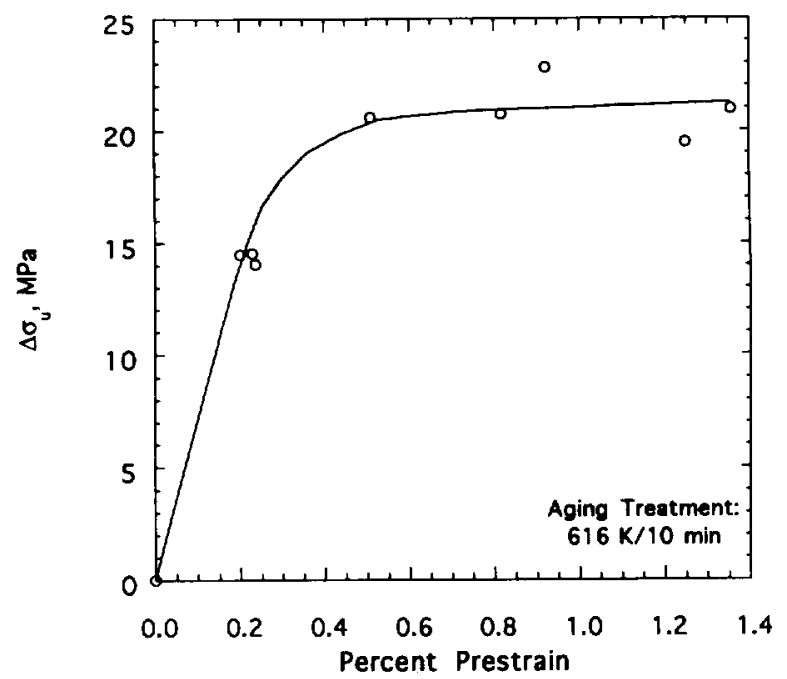

Fig. 3. Influence of $\%$ prestrain at room temperature followed by aging at $616 \mathrm{~K} / 10 \mathrm{~min}$ on the subsequent yield stress increment measured at room-temperature. mens were often aged several times to obtain a $\Delta \sigma_{\mathrm{u}}$-time relationship. A specimen previously tested or prestrained uniaxially was given a recovery anneal, typically $1100 \mathrm{~K} / 1800 \mathrm{~s}(30 \mathrm{~min}) / \mathrm{AC}$, prestrained approximately $0 \cdot 2 \%$, aged in situ and re-tested at room temperature. A typical series of stress-strain curves illustrating this procedure are shown in Fig. 2. When this type of testing is adopted, the yield point exhibited during the original deformation of the material can be recovered as can the yield point increment observed during the previous test. This means that it is possible to recover the dislocation structure and obtain a reproducible $\Delta \sigma_{u}$ following the same strain aging (i.e. prestrain + annealing) treatment, justifying the use of multiple deformation experiments on single samples.

\section{RESULTS}

Figure 3 shows the influence of prior strain on the resulting yield stress increment, $\Delta \sigma_{u}$, after aging of the $\mathrm{CP}-\mathrm{NiAl}$ at $616 \mathrm{~K}$. Increasing the amount of prior strain in samples aged at $616 \mathrm{~K}$ for $600 \mathrm{~s}$, for example, leads initially to a rapid increase in $\Delta \sigma_{\mathrm{u}}$ followed by an apparent plateau at prestrains exceeding $0.5 \%$. Strain dependence of this type, which has been classified as type $\mathrm{S}$ by Kubin et al. ${ }^{26}$ is commonly observed in bcc alloys and is often associated with elastic interactions between dislocations and solute atoms.

The time dependence of $\Delta \sigma_{\mathrm{u}}$ for the CP material is shown in Fig. 4. The data is summarized in

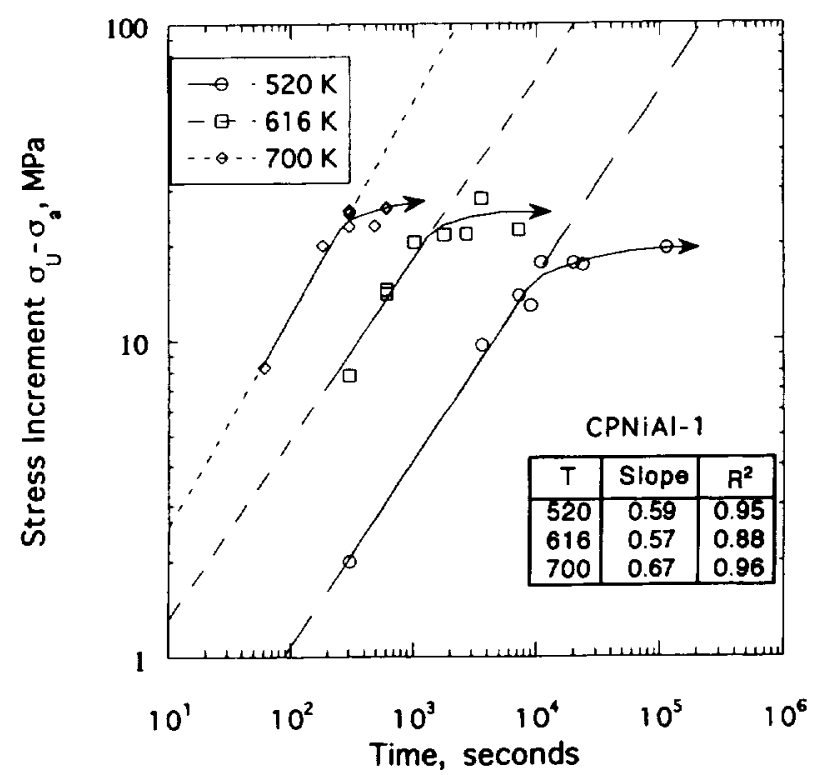

Fig. 4. In $\Delta \sigma_{u}$ vs. In $t$ for CP-NiAl specimens. Specimens were prestrained uniaxially in tension to $0.2 \%$ prior to the strain aging treatments. The least squares parameters are indicated on the figure. 
Table 2. The shapes of the aging curves up to the maximum value of $\Delta \sigma_{\mathrm{u}}$ are comparable to similar curves reported for bcc metals. ${ }^{27}$ Under type S conditions, ${ }^{26} \Delta \sigma_{u}$ will increase proportionally with $t^{2 / 3}$ during the early stages of aging, assuming $\Delta \sigma_{\mathrm{u}}$ is proportional to the amount of solute segregating to dislocations. At longer times, the dislocations will become saturated with solute leading to a plateau in $\Delta \sigma_{u}$ or even to a decrease in $\Delta \sigma_{u}$ due to precipitation. The strain aging time exponent, as determined by least squares analysis of the data prior to saturation in Fig. 4 , is in the range 0.57 to 0.67 which is close to the theoretical value of $2 / 3$ predicted by Cottrell and Bilby. ${ }^{3}$ In confirmation of this result, $\Delta \sigma_{\mathrm{u}}$ is plotted versus $t^{2 / 3}$ in Fig. 5 demonstrating the satisfactory fit. Although experiments were only performed at $610 \mathrm{~K}$ for NiAl-C, a similar trend of higher $\Delta \sigma_{\mathrm{u}}$ with increasing aging time was observed (Fig. 6 and Table 3). In addition, the time exponent was found to be 0.59 in agreement with the observations for $\mathrm{CP}-\mathrm{NiAl}$.

The $\Delta \sigma_{u}$ versus log time data for $\mathrm{CP}-\mathrm{NiAl}$ and $\mathrm{NiAl}-\mathrm{C}$ that were aged for various times at 616 and $610 \mathrm{~K}$, respectively, are plotted together in

Table 2. The temperature dependence of the yield stress increment for $\mathrm{CP}-\mathrm{NiAl}$

\begin{tabular}{|c|c|c|}
\hline $\begin{array}{c}\text { Aging temperature, } \\
\mathrm{K}\end{array}$ & $\underset{\mathrm{S}}{\text { Aging time, }}$ & $\begin{array}{c}\text { Yield stress increment } \\
\text { MPa }\end{array}$ \\
\hline 520 & 300 & 2 \\
\hline 520 & 3600 & 10 \\
\hline 520 & 7200 & 14 \\
\hline 520 & 9000 & 13 \\
\hline 520 & 10800 & 18 \\
\hline 520 & 19800 & 18 \\
\hline 520 & 23400 & 17 \\
\hline 520 & 113400 & 20 \\
\hline 616 & 300 & 8 \\
\hline 616 & 600 & 14 \\
\hline 616 & 600 & 15 \\
\hline 616 & 600 & 15 \\
\hline 616 & 1020 & 20 \\
\hline 616 & 1800 & 22 \\
\hline 616 & 2700 & 22 \\
\hline 616 & 3600 & 28 \\
\hline 616 & 7200 & 22 \\
\hline 616 & 11880 & 22 \\
\hline 616 & 59820 & 25 \\
\hline 700 & 60 & 8 \\
\hline 700 & 180 & 20 \\
\hline 700 & 300 & 23 \\
\hline 700 & 300 & 26 \\
\hline 700 & 300 & 25 \\
\hline 700 & 480 & 23 \\
\hline 700 & 600 & 26 \\
\hline 700 & 600 & 26 \\
\hline 700 & 7200 & 24 \\
\hline 700 & 61200 & 23 \\
\hline
\end{tabular}

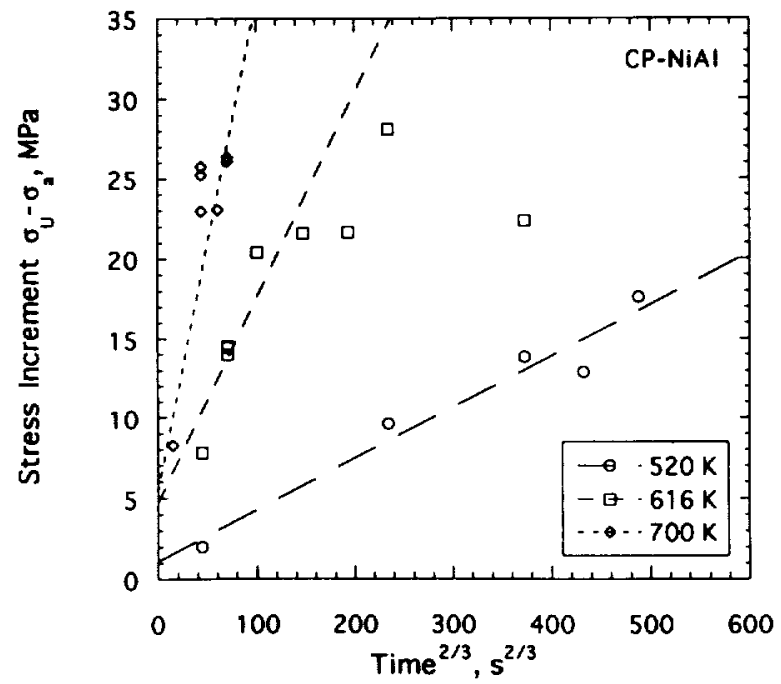

Fig. 5. Plots of $\Delta \sigma_{u}$ vs $t^{2 / 3}$ for CP-NiAl aged at 520,616 , and $700 \mathrm{~K}$.

Fig. 6 to illustrate the influence of carbon concentration on the yield point return in NiAl. A significant difference in the magnitudes of the $\Delta \sigma_{u}$ 's is evident as is an increase in the time required for yield points to form in NiAl-C. In addition, the saturation stress increment is lower

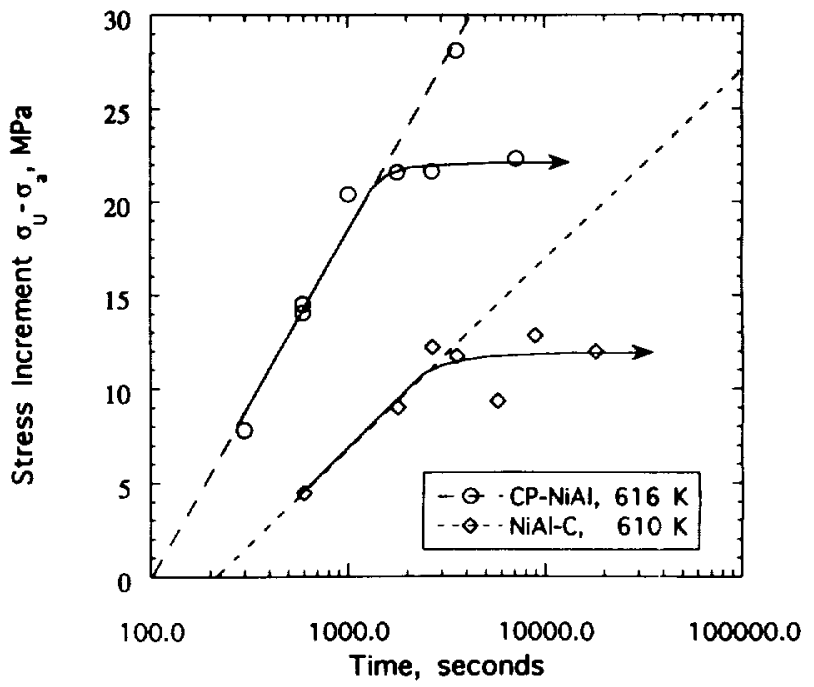

Fig. 6. Plot of $\Delta \sigma_{u}$ vs natural $\log t$ for $\mathrm{CP}-\mathrm{NiAl}$ and NiAl-C at $616 \mathrm{~K}$ and $610 \mathrm{~K}$, respectively.

Table 3. Temperature dependence of yield stress increment for NiAl-C

Aging temperature, Aging time, Yield stress increment,

\begin{tabular}{crr}
$K$ & $\mathrm{~s}$ & $\mathrm{MPa}$ \\
\hline 610 & 600 & 5 \\
610 & 1800 & 9 \\
610 & 3600 & 12 \\
610 & 4500 & 12 \\
610 & 5760 & 9 \\
610 & 9000 & 13 \\
610 & 18360 & 12
\end{tabular}


in NiAl-C than in CP-NiAl. This behavior would be expected since NiAl-C has only about $2 / 3$ the $\mathrm{C}$ level of CP-NiAl.

In an effort to establish a mechanism for static strain aging in NiAl, the activation energy for the return of the lower yield stress was determined by applying an Arrhenius equation which is derived from the expression of Cottrell and Bilby ${ }^{3}$ for the number of atoms per length of dislocation line segregating into the vicinity of a dislocation in time $t$ :

$$
n(t)=\mathrm{a} N_{\mathrm{o}}\left(\frac{A D t}{k T}\right)^{2 / 3}
$$

where, $\alpha \cong 3 \cdot 5, N_{\mathrm{o}}$ is the average volumetric concentration of defects in the lattice, $D$ is the diffusivity of the defect at the aging temperature, $T, k$ is Boltzmann's constant and $A$ is a term corresponding to the binding energy between the defect and a dislocation. If prestraining and subsequent reloading are conducted at the same temperatures and if these temperatures are sufficiently low so that no aging occurs during testing, the number of defects required to pin a unit length of a dislocation line, $n\left(t^{*}\right)$, will be approximately constant. Thus, eqn (1) becomes:

$$
C_{1}=\left(\frac{n\left(t^{*}\right)}{N_{\mathrm{o}} \alpha}\right)^{3 / 2}\left(\frac{k}{A D_{\mathrm{o}}}\right)=\frac{t^{*}}{T} \exp \left(\frac{-Q}{R T}\right)
$$

where $D_{\mathrm{o}}$ is the pre exponential factor for diffusivity of the defect and $t^{*}$ represents the aging time for the reappearance of a yield point. Equation (2) can then be rewritten as:

$$
\ln \left(\frac{T}{t^{*}}\right)=\ln \left(\frac{1}{C_{1}}\right)-\frac{Q}{R T}
$$

The activation energy for diffusion of the pinning defect, $Q$, is determined from the slope of a plot of $\ln \left(T / t^{*}\right)$ versus $1 /(R T)$. This method is illustrated in Fig. 7. On this basis, an activation energy for the return of a lower yield point in CP$\mathrm{NiAl}$ was determined to be in the range 72 to 76 $\mathrm{kJ} /$ mole (approximately 0.75 to $0.79 \mathrm{eV} /$ atom), which corresponds to the activation energies for the migration of interstitials in many bcc transition metals. ${ }^{28}$

As an alternative approach to the Arrhenius calculation, the activation energy was also determined by the method used by Hartley ${ }^{29}$ who modified the Cottrell-Bilby relationship for the yield stress increment as follows:

$$
\frac{\Delta \sigma_{\mathrm{u}}}{\bar{\sigma}}=\frac{\left(\sigma_{\mathrm{u}}-\sigma_{\mathrm{a}}\right)}{1 / 2\left(\sigma_{\mathrm{a}}+\sigma_{\mathrm{u}}\right)}=K_{1}+K_{2}\left(\frac{t}{T_{\mathrm{a}}}\right)^{2 / 3}
$$

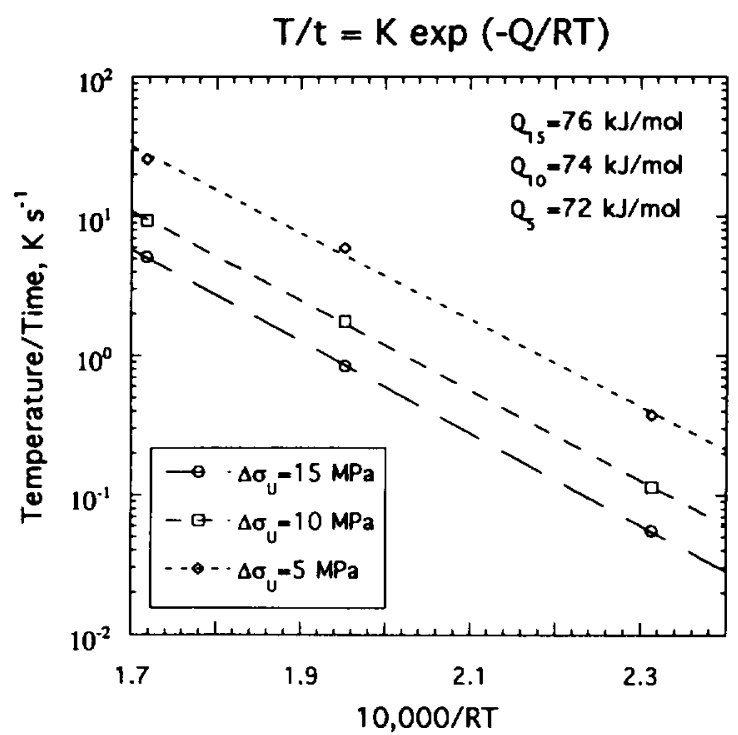

Fig. 7. Arrhenius representation of the strain aging data for CP-NiAl.

where $K_{1}$ is a constant, $K_{2}$ is a constant proportional to $D^{2 / 3}$, where $D$ is the diffusivity, $t$ is the aging time, and $T_{\mathrm{a}}$ is the aging temperature. Recalling that $D=D_{\mathrm{O}} \exp (-Q / R T)$, activation energies are calculated by first determining the slope $S_{1}$ of a plot of $\Delta \sigma_{u} \bar{\sigma}$ versus $t^{2 / 3}$ and then by plotting $\ln \left(S_{1} T^{2 / 3}\right)$ versus $2 /(3 R T)$. This method is illustrated in Fig. 8. Using this approach, an activation energy of $70 \mathrm{~kJ} / \mathrm{mol}(0.73 \mathrm{eV} / \mathrm{atom})$ was determined which is in good agreement with the value established using the Arrhenius method.

Due to the lack of diffusion data for any type of interstitial solute in $\mathrm{NiAl}$, little can be said about the activation energies derived in this investigation except that these values lie below the self diffusion energies for $\mathrm{Ni}$ and $\mathrm{Al}$ in $\mathrm{NiAl}$ and that they lie well below the activation energy for the creation and motion of vacancies. ${ }^{20}$ However, the activation energies derived in this study are within the range for interstitial diffusion in bcc transition metals. $^{28}$

\section{DISCUSSION}

Previously, it was shown that the discontinuous yielding observed in $\mathrm{CP}-\mathrm{NiAl}$ and $\mathrm{NiAl}-\mathrm{C}$ was the result of strong dislocation pinning by interstitial carbon, ${ }^{12}$ whereas increased concentrations of oxygen and/or nitrogen had little or no influence on the properties of nominally stoichiometric $\mathrm{NiAl}{ }^{12.30 .31}$ Therefore, $\mathrm{C}$ has been identified as the major solute responsible for strain aging effects in NiAl. ${ }^{12,25}$ In addition, it has been observed 


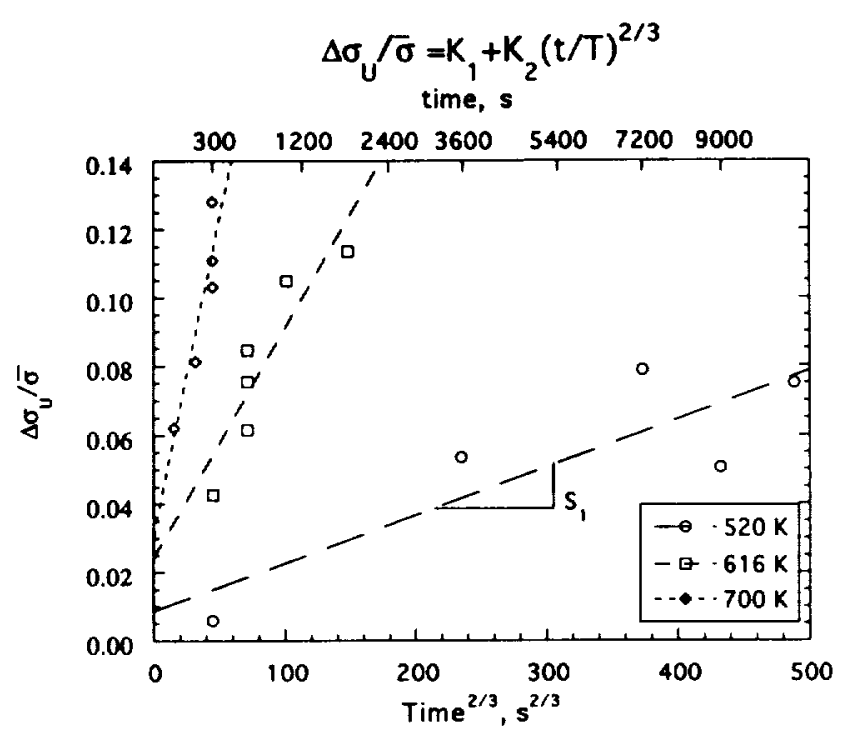

of interstitial atoms to dislocations so as to form solute atmospheres around the dislocations. The driving force for this process is the reduction in strain energy of the system. Yield points form when the available dislocations are effectively locked by these solute atmospheres. The resulting increase in yield stress is due either to an increased stress required to move the locked dislocations or an increase in stress necessary to nucleate new dislocations permitting macroscopic plastic flow. The initial locking of dislocations requires long range diffusion of interstitials to the vicinity of dislocations and, as a result, requires many atom jumps. During the early stages of Cottrell locking, the kinetics of yield point return normally increase with time according to a $t^{2 / 3}$ power law. This relationship was originally deduced by Cottrell and Bilby $^{3}$ and has been confirmed for a number of

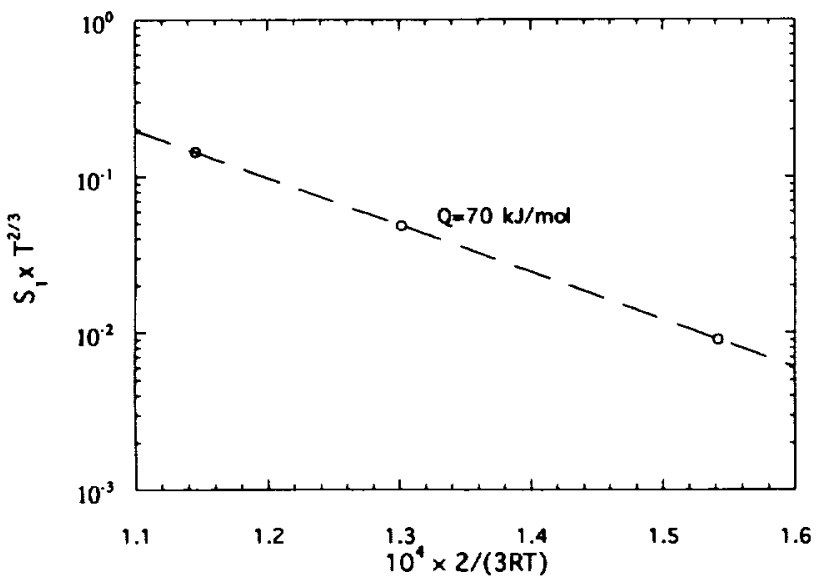

Fig. 8. Demonstration of the Hartley method ${ }^{29}$ for determination of the activation energy for yield point return. (a) Strain aging parameters versus $i^{2 / 3}$ for CP-NiAl aged at 520,616 and $700 \mathrm{~K} ;$ (b) determination of the activation energy for yield point return using the Hartley method.

that longer aging times are required in NiAl-C to achieve the same yield stress increment as observed in CP-NiAl and that the yield increment after saturation is much greater in CP-NiAl than in NiAl-C. It is believed that this behavior is a result of the significant reduction in the concentration of interstitials, particularly $\mathrm{C}$, in the NiAl-C alloy. Since there is less carbon to pin dislocations in NiAl-C, the carbon present must, presumably, diffuse longer distances to cause pinning.

At least four different mechanisms have been postulated to explain strain-aging in metals and alloys. These include: (1) the formation of Cottrell atmospheres, ${ }^{3}$ (2) Snoek ordering, ${ }^{1.2 .32}$ (3) Suzuki locking, ${ }^{4}$ and (4) the precipitation of solute on dislocations. ${ }^{33}$

Cottrell locking or aging involves the diffusion systems involving interstitial atoms in transition metals including $\mathrm{Nb}-\mathrm{O}, \mathrm{Ni}-\mathrm{H}, \mathrm{Fe} \mathrm{C}$ and $\mathrm{Fe}-\mathrm{N} .^{27,32.34 \cdot 38}$ The observed $\log t$ or approximate $t^{2 / 3}$ time dependence of $\Delta \sigma_{\mathrm{u}}$ in $\mathrm{NiAl}$ due to carbon is consistent with the Cottrell-Bilby theory and suggests that Cottrell locking is the mechanism responsible for the observed yield points.

Snoek ordering of impurity atoms within the stress field of a dislocation remains a possible mechanism that may occur prior to the formation of a Cottrell atmosphere. This mechanism is best explained in terms of the Snoek effect as it occurs in bcc metals containing interstitial atoms in solution. ${ }^{1,2,32}$ In the bcc lattice the tetrahedral sites are larger than the octrahedral sites. However, interstitial atoms typically occupy the smaller octahedral sites at the center of cube edges and cube faces because the lattice strain caused by octahedral occupancy can be more easily accommodated by the lattice than that caused by tetrahedral occupancy. For example, the insertion of an interstitial atom into the $1 / 2,1 / 2,0$ position in Fig. 9 will cause atoms 1 and 2 to be displaced apart in the $z$ direction resulting in a tetragonal distortion, whereas the insertion of an interstitial into the $1 / 2$, 0,0 position will cause a more uniform distortion of substitutional atoms 1-4. In the absence of an applied stress, a statistically equal number of interstitials will occupy sites parallel to each of the $x, y$ and $z$ axes. Thus, the unit cell remains cubic. The application of an external stress in the $z$ direction, for example, causes the interstitial sites parallel to the $z$ axis to enlarge while the openings perpendicular to the $z$ axis decrease in size making it energetically more favorable for atoms at the $1 / 2,1 / 2,0$ position, for example, to jump to the 
$1 / 2,0,1 / 2$ position. This is known as the Snoek effect or Snoek ordering. ${ }^{1,2}$ Since no long range diffusion is required, this process occurs very rapidly and is normally completed within the time interval of one atomic jump of the species responsible for pinning.

Similar behavior will be observed in B2 alloys. As in the case of bcc described above, an atom placed in an octahedral site results only in displacement of the two nearest atoms, whereas tetrahedral occupancy results in the distortion of the four neighboring atoms. Baker, ${ }^{39}$ however, indicates that in the B2 crystal structure octahedral sites are not equivalent. Assuming that the A metal atoms represent $\mathrm{Ni}$ and the $\mathrm{B}$ metal atoms represent $\mathrm{Al}$ (i.e., $R_{\mathrm{B}}>R_{\mathrm{A}}$ ), the octahedral sites defined by $\mathrm{Ni}$ atoms will always be larger than those defined by $\mathrm{Al}$ atoms. In other words, an interstitial will prefer to occupy the octahedral position at 1/2,1/2, 0 (face) in the $\mathrm{B} 2$ lattice illustrated in Fig. 9 as opposed to the 1/2, 0, 0 (edge) position because this site is larger than the edge position and allows for easier accommodation of an interstitial atom. However, even if the interstitials prefer only half of the total octahedral sites, the effect of stress on these remaining sites would still be the same as that described in the previous paragraph and Snoek ordering should still occur. Nakada and $\mathrm{Keh}^{35}$ have indicated that the apparent intercept of the $\Delta \sigma_{\mathrm{u}}$ versus $t^{2 / 3}$ curves is positive when Snoek ordering occurs prior to Cottrell

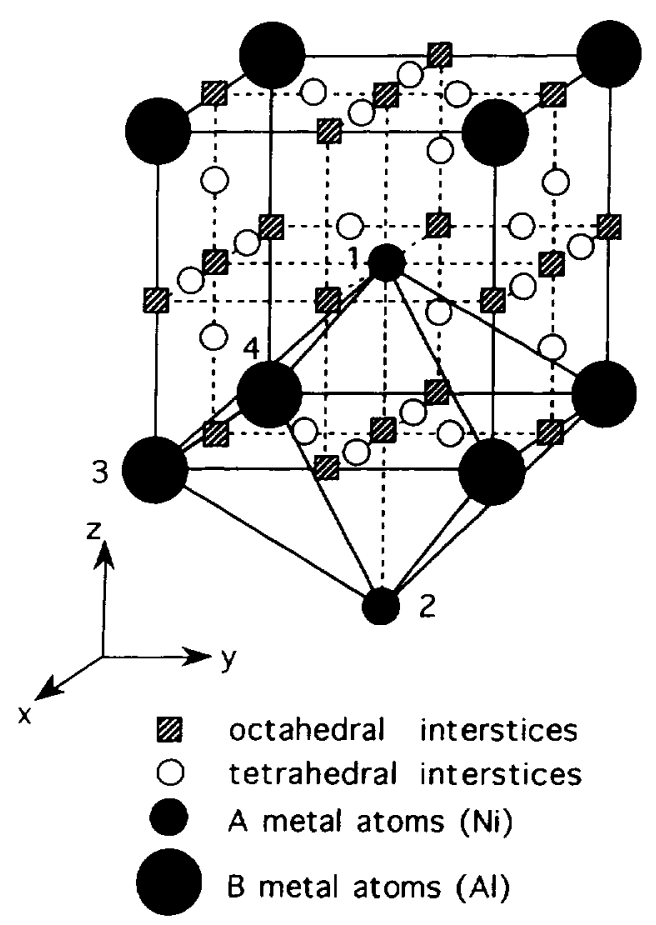

Fig. 9. Schematic illustration of the octahedral and tetrahedral interstitial sites in the bcc/B2 unit cell. atmosphere formation. In Fig. 5, a positive intercept of the $\Delta \sigma_{\mathrm{u}}$ versus $t^{2 / 3}$ curve is observed which suggests that some degree of Snoek ordering does occur in $\mathrm{NiAl}$ prior to the aforementioned Cottrell locking.

Suzuki locking is inapplicable to the present investigation. This mechanism has its origin in a chemical interaction between solute atoms and stacking faults and is only expected to be significant in metals of low stacking fault energy in which the stacking fault widths are large.

Precipitation on dislocations as a result of the segregation of solute would appear to be inappropriate because precipitates were not observed in thin foils made from specimens of $\mathrm{CP}-\mathrm{NiAl}$ and NiAl-C aged at $1100 \mathrm{~K} 7200 \mathrm{~s} / \mathrm{FC}$ or $610 \mathrm{~K} 7200$ $\mathrm{s} / \mathrm{AC}$. In addition, the shapes of the aging curves for $\mathrm{CP}-\mathrm{NiAl}$ and $\mathrm{NiAl}-\mathrm{C}$ for aging times up to $61000 \mathrm{~s}$ at $700 \mathrm{~K}$ (Fig. 4 and 6) do not suggest the formation of precipitates since a decrease in $\Delta \sigma_{\mathrm{u}}$ that could be attributed to overaging and coarsening of any precipitates present was not observed at longer aging times. This does not preclude such a mechanism in alloys containing higher levels of substitutional contaminants as well as interstitial carbon..$^{40-42}$ However, precipitation was not observed within the time-temperature range examined for alloys with the specific compositions studied in this investigation.

Therefore, assuming a Cottrell type pinning mechanism does occur, additional kinetic information about $\mathrm{C}$ diffusion in $\mathrm{NiAl}$ can be obtained from the data generated during this study. Using the activation energies calculated above, it becomes possible to estimate the amount of enrichment at the dislocation core after strain aging. Assuming that the segregation of interstitials to a dislocation core is described by a Maxwellian distribution ${ }^{43}$ where the solute concentration at the dislocation core, $c$, is determined according to:

$$
c=c_{\mathrm{o}} \exp \left(\frac{-W \mathrm{~m}}{R T}\right)
$$

where $c_{o}$ represents the bulk solute concentration in the crystal, $R$ is the universal gas constant, $T$ is the absolute temperature and $W_{\mathrm{m}}$ is the dislocation-solute binding energy. Though $W_{\mathrm{m}}$ is currently unknown, a rough estimate can be obtained by substituting into eqn (5) the temperature above which yield point phenomena are not observed, $T_{\max }$ (which turns out to be approximately $900 \mathrm{~K}$ for $\mathrm{CP}-\mathrm{NiAl}$ ), and by setting $c$ equal to unity. This results in an estimated $W_{\mathrm{m}}$ of $51 \mathrm{~kJ} / \mathrm{mol}(0.5$ $\mathrm{eV} /$ atom) which is a reasonable estimate when 
compared to similar numbers generated for bcc metals using the same assumptions. ${ }^{28.43}$ Using this estimated value for $W_{\mathrm{m}}$, an expression for the solute enrichment at the dislocation core after strain aging for time $t_{\mathrm{a}}$ at temperature $T$ can be derived as follows: ${ }^{43}$

$$
c-c_{\mathrm{o}}=\frac{\pi c_{\mathrm{o}}}{b^{2}}\left[\frac{n(n+2) D\left|W_{\mathrm{m}}\right| b^{n} t_{a}}{R T}\right]^{n /(n+2)}
$$

where $b$ represents the Burgers vector of the dislocations and $n$ is a material parameter used to characterize the type of dislocation-solute interaction. For interactions due to size effects, as in this case, $n=1$. The time required to saturate a dislocation at temperatures sufficiently low enough for stable saturation to occur is given by the condition $c=c_{1}>c_{0}$ where $c_{1}$ is the critical solute concentration for saturation and is less than unity. Assuming that the carbon atoms (impurities) attract each other then $c_{1}=1 / 2$ and the saturation time, $t_{\mathrm{s}}$, is related to the solute diffusivity as follows: ${ }^{43}$

$$
t_{\mathrm{s}} \cong\left(\frac{c_{1}}{\pi c_{\mathrm{o}}}\right)^{n+2} \frac{R T b^{2}}{n(n+2) D\left|W_{\mathrm{m}}\right|}
$$

Assuming that $t_{\mathrm{s}}$ corresponds to the minimum aging time required to induce yield point phenomena (i.e., sharp yield points or pronounced yield plateaus in the stress-strain curves), it becomes possible to calculate an upper bound for the diffusion coefficients for carbon in NiAl using the $T$ and $t_{\mathrm{s}}$ values determined during this investigation and listed in Table 4 . The resulting $D$ values are also listed in Table 4. A linear least squares fit of In $D$ versus $1 /(R T)$ using the values in Table 4 yields

$$
D=\left(6 \times 10^{9}\right) \exp \left(\frac{-Q}{R T}\right)
$$

where the activation energy, $Q$, turn out to be 74 $\mathrm{kJ} / \mathrm{mol}(0.77 \mathrm{eV} /$ atom $)$ which is equivalent to the values derived from the $\Delta \sigma_{\mathrm{u}}$ vs $t$ data in the results section. Furthermore, in the regime where static strain aging has been shown to occur in CP-NiAl, the calculated diffusivities of carbon in $\mathrm{NiAl}$, are at least numerically equivalent to the diffusivities

\section{Table 4. Calculated diffusion coefficients for $\mathrm{C}$ in NiAl}

\begin{tabular}{ccc}
\hline Temperature $(\mathrm{K})$ & $t_{\mathrm{s}}, \mathrm{s}$ & $D \mathrm{~cm}^{2} \mathrm{~s}^{1}$ \\
\hline 522 & 3600 & $2 \times 10^{16}$ \\
616 & 300 & $3 \times 10^{15}$ \\
700 & 60 & $2 \times 10^{14}$
\end{tabular}

of carbon in alpha iron within the strain aging regime (i.e., approximately $10^{-17} \mathrm{~cm}^{2} \mathrm{~s}^{-1}$ at $298 \mathrm{~K}$ to approximately $10^{-10} \mathrm{~cm}^{2} \mathrm{~s}^{-1}$ at $573 \mathrm{~K}^{44}$

\section{SUMMARY AND CONCLUSIONS}

(1) The observed $\log t$ or approximate $t^{2 / 3}$ time dependence of $\Delta \sigma_{\mathrm{u}}$ in $\mathrm{NiAl}$ due to carbon is consistent with the Cottrell-Bilby theory which suggests that Cottrell locking is the mechanism responsible for the observed yield points. In addition, positive intercepts on plots of $\Delta \sigma_{\mathrm{u}}$ versus $t^{2 / 3}$ suggests that Snoek ordering also occurs prior to Cottrell train aging.

(2) Activation energies for yield point return ranging from 70 to $76 \mathrm{~kJ} / \mathrm{mol}(0.73$ to 0.79 $\mathrm{eV}$ atom $^{-1}$ ) have been calculated by two different techniques. These values are in the range for the diffusion of interstitials in bcc transition metals.

\section{ACKNOWLEDGEMENTS}

This research was sponsored by the NASA-Lewis Research Center under Grant NGT-2958. Helpful discussions with B. F. Oliver (UT), R. E. ReedHill (UF), A. J. Duncan (UF), V. Levit (UF), J. E. Hack (YU) and R. M. Dickerson (CWRU) are gratefully acknowledged. The authors are also indebted to B. F. Oliver for supplying the NiAl-C alloy.

\section{REFERENCES}

1. Snoek, J., Physica, 6 (1939) 591.

2. Snoek, J.. Physica, 8 (1941) 711.

3. Cottrell, A. H. \& Bilby, B. A., Proc. of the Physical Society, London, A62 (1949) 49.

4. Suzuki, H., in Dislocations and Mechanical properties of Crystals. John Wiley and Sons, New York, 1957.

5. Hack, J. E., Brzeski, J. M., Darolia, R. \& Field, R. D., High-Temperature Ordered Intermetallics $V$, eds I. Baker, R. Darolia, J. D. Whittenberger \& M. H. Yoo. Materials Research Society, Boston, MA, 1993, p. 1197.

6. Lautenschlager, E. P., Kiewit, D. A. \& Brittain, J. O., Trans. AIME, 233 (1965) 129 ?

7. Margevicius, R. W. \& Lewandowski, J. J., Scripta. Metall. Mater., 25 (1991) 2017.

8. Field. R. D., Lahrman, D. F. \& Darolia, R., High-Temperature Ordered Intermetallic Alloys $V$, eds I. Baker, R. Darolia, J. D. Whittenberger \& M. H. Yoo. Materials Research Society, Boston, MA, 1993, p. 423.

9. Brzeski, J. M., Hack, J. E., Darolia, R. \& Field, R. D., Mater. Sci. Eng., A170 (1993) 11. 
10. Liu, C. T., Lee, E. H., George, E. P. \& Duncan, A. J., Scripta Metall. Mater, 30 (1994) 387.

11. Hack, J. E., Brzeski, J. M. \& Darolia, R., Mater. Sci. Eng., A192/193 (1995) 268.

12. Weaver, M. L., Noebe, R. D., Lewandowski, J. J., Oliver, B. F. \& Kaufmann, M. J., Mater. Sci. Eng., A192/193 (1995) 179 .

13. Gaydosh D. J., Draper, S. L., Noebe, R. D. \& Nathal, M. V., Mater. Sci. Eng., A150 (1992) 7.

14. Morris, D. G., Joye, J. C. \& Leboeuf, M., Philos. Mag. A, 69 (1994) 961.

15. Wood, D. L. \& Westbrook, J. H., Trans. Metall. Soc. AIME, 224 (1962) 1024.

16. Dinhut, J. F., Lepinay, P. \& Desoyer, J. C., Phys. Stat. Sol. $A, 55$ (1979) 621.

17. Pascoe, R. T. \& Newey, C. W. A., Metall. Sci. J., 2 (1968) 138.

18. Pascoe, R. T. \& Newey, C. W. A., Metall. Sci. J., 5 (1971) 50

19. Kitano, K., Pollock, T. M. \& Neobe, R. D., Scripta Metall. Mater., 31 (1994) 397.

20. Noebe, R. D., Bowman, R. R. \& Nathal, M. V., Int. Mater. Rev., 38 (1993) 193.

21. Weaver, M. L., The Effect of Molybdenum Additions on the Mechanical Behavior of NiAl. University of Florida. Progress Report, August 1 to September 15, (1993).

22. Margevicius, R. W., Lewandowski, J. J., Locci, I. E. \& Noebe, R. D., Scripta Metall. Mater., 29 (1993) 1309.

23. Margevicius, R. W. \& Lewandowski, J. J., Acta Metall. Mater., 41 (1993) 485.

24. Margevicius, R. W., Lewandowski, J. J. \& Locci, I. E., Structural Intermetallics, eds R. Darolia, J. J. Lewandowski, C. T. Liu, P. L. Martin, D. B. Miracle \& M. V. Nathal. The Minerals, Metals and Materials Society, Seven Springs, PA, 1993, p. 577.

25. Weaver, M. L., Noebe. R. D.. Lewandowski, J. J.,
Oliver, B. F. \& Kaufman, M. J., submitted to Intermetallics.

26. Kubin, L. P., Estrin, Y. \& Perrier, C., Acta Metall. Mater., 40 (1992) 1037.

27. Baird, J. D., Metall. Rev., 16 (1971) 1.

28. Schultz, H., Mater. Sci. Eng., 3 (1968/69) 189.

29. Hartley, S., Acta Metall., 14 (1966) 1237.

30. Noebe, R. D. \& Garg, A., Scripta Metall. Mater, 30 (1994) 815 .

31. Cooper, R. M., Sikka, V. K. \& Noebe, R. D., in Advances in Powder Metallurgy and Particulate Materials 1994. American Powder Metallurgy Institute, Princeton, NJ, 1994/5.

32. Schoeck, G. \& Seeger, A., Acta Metall, 7 (1959) 469.

33. Hall, E. O., Yield Point. Phenomena in Metals and Alloys. Plenum Press, New York, 1970.

34. Park, S. C., Beckerman, L. P. \& Reed-Hill, R. E.. Metall. Trans. A, 14A (1983) 463

35. Nakada, Y. \& Keh, A. S., Acta Metall. 15 (1967) 879.

36. Rosinger, H. E., Craig, G. B. \& Bratina, W. J., Mater. Sci. Eng., $5(1969 / 70) 163$.

37. Rosinger, H. E., Metal. Sci, 9 (1975) 1.

38. Keh, A. S., Nakada, Y. \& Leslie, W. C., in Dislocation Dynamic's, eds. A. R. Rosenfield, G. T. Hahn, A. L. Bement \& R. I. Jaffee. McGraw-Hill Book Company, New York, 1968, p. 381.

39. Baker, I., J. Mater. Res., 8 (1993) 1203.

40. DeMarco, H. K., Ardell, A. J. \& Noebe, R. D., Mater. Sci. Eng. in press (1995).

41. Duncan, A. J., Kaufman, M. J. \& Miller, M. K., Appl. Surf. Sci. 76/77 (1994) 160.

42. Jayaram, R. \& Miller, M. K., Acta Metall. Mater., 42 (1994) 1561.

43. Friedel, J., Dislocations. Pergamon Press, Oxford, 1964.

44. Leslie, W. C.. The Physical Metallurgy of Steels. McGraw-Hill, New York, 1981. 
